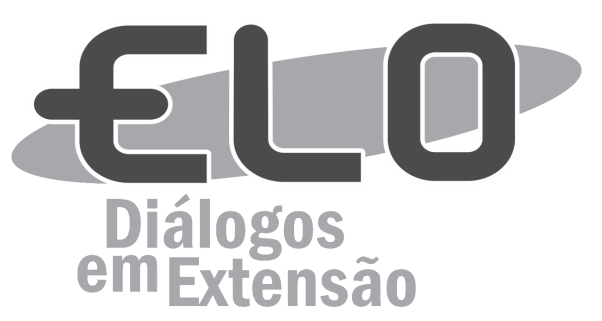

\title{
Literatura e extensão: processo essencial na formação de leitores
}

Cibele Hechel Colares da Costa ${ }^{1}$, Fernanda Machado Johannsen ${ }^{2}$, Mairim Link Piva ${ }^{3}$

\begin{abstract}
Resumo: O relato aponta reflexões sobre a prática de cursos de extensão na área de Literatura, desenvolvidos na Universidade Federal do Rio Grande (entre 2007 e 2015), vinculados ao Instituto de Letras e Artes. Análises de Aguiar e Bordini (1993), Candido (2004) e Lajolo e Zilberman (1996, 2001 e 2009) norteiam alguns dos pontos sobre leitura e formação de leitores que estão na base de nossa práxis enquanto coordenadora $e$ docentes envolvidas nos projetos extensionistas. As atividades visam despertar o prazer relacionado ao ato da leitura, bem como ampliar a relação entre a formação de leitores e a ampliação da inserção social de indivíduos atuantes na sociedade.
\end{abstract}

Palavras-chave: Curso de extensão. Literatura. Formação de Leitores.

Área Temática: Literatura e educação.

\section{Literature and scope: essential process in the formation of readers}

Abstract: The experience report reflects about the activities in the extension courses in the literature area, developed in the Universidade Federal do Rio Grande, bound to Instituto de Letras e Artes. Analysis from Aguiar and Bordini (1993), Candido (2004) and Lajolo and Zilberman (1996, 2001, and 2009), guide some of the topics about reading and the reader formation in our work as coordinator and teachers of the extensionist projects. The activities aim to awake the pleasure of reading, as well as stimulating the relation btween the readers formation and the increasing of the social insertion of acting individuals in the society.

Keywords: Extension courses. Literature. Readers formation.

\section{Literatura y alcance: proceso esencial en la formación de lectores}

Resumen: El informe señala reflexiones sobre la práctica de los cursos de extensión en el área de Literatura, desarrollado en la Universidade Federal de Rio Grande, vinculado al Instituto de Letras e Artes. Análisis Aguiar y Bordini (1993), Candido (2004) y Lajolo y Zilberman (1996, 2001 y 2009) que guía algunos de los puntos sobre la lectura y la formación jugadores que son la base de nuestra práctica como coordinador y los profesores implicados en el proyecto de ampliación. Las actividades tienen como objetivo despertar el placer relacionado con el acto de la lectura, así como ampliar la relación entre la formación de lectores y la expansión de la inclusión social de las personas activas en la sociedad.

Palabras clave: Curso de extensión. Literatura. Lectores de Formación.

\footnotetext{
Doutoranda em Letras, pela Universidade Federal do Rio Grande. Endereço residencial: Rua Dom Bosco, 1017 - Bloco 02 Apto 307 - Cohab II - CEP: $96211-092$ - Rio Grande/RS. Endereço eletrônico: cibele_colares@yahoo.com.br. Telefone: (53) 8409-1247

${ }^{2}$ Mestranda em Letras, pela Universidade Federal do Rio Grande.

${ }^{3}$ Professora Adjunta da Universidade Federal do Rio Grande, vinculada ao Instituto de Letras e Artes, coordenadora dos projetos de extensão mencionadas nesse relato.
} 


\section{Introdução}

O relato trata dos cursos de extensão na área dos estudos literários oferecidos na Universidade Federal do Rio Grande (FURG), desde 2007. Os cursos são coordenados por professores do Instituto de Artes e Letras (ILA) e ministrados por acadêmicos em nível de graduação, mestrado e doutorado da área de Letras e afins.

\section{Objetivos}

Este artigo tem como objetivo central relatar as atividades extensionistas desenvolvidas na área dos estudos literários oferecidos na Universidade Federal do Rio Grande (FURG), desde 2007. Bem como fazer um levantamento dessas práticas para que o grupo envolvido possa ter um panorama (e um registro, com essa publicação) do que já foi realizado e avançar em próximas ações.

\section{Metodologia}

O presente trabalho foi construído a partir de uma revisão bibliográfica com o foco na leitura e na formação de leitores. Além disso, foram utilizados os registros realizados pelas docentes dos cursos extensionistas para auxílio na exposição dos resultados obtidos ao longo da realização das atividades.

\section{Resultados e Discussões}

No ano de 2007, desenvolveu-se o curso de "Literatura sul-rio-grandense" com a finalidade de oportunizar um espaço propício para o debate sobre literatura relacionado, em um primeiro momento, com as pesquisas desenvolvidas pelas professoras ministrantes, fazendo assim, um elo entre ensino, pesquisa e extensão. Ao final do curso, os alunos solicitaram o oferecimento de novas atividades direcionadas à área de Letras. Esse curso teve o papel de incentivador para que ocorressem outras edições no âmbito da Literatura.

Em 2011, ocorreu a reoferta do curso de "Literatura Sul-rio-grandense", nesse momento acrescido do vocábulo "Contemporânea", dado o enfoque em obras de autores contemporâneos da literatura gaúcha. Essa temática foi estimulada pelo vínculo com projetos e linhas de pesquisas do Programa de Pós-Graduação do ILA. Nessa edição, o curso foi dividido por módulos que abarcavam dois escritores sulinos cada para leituras analíticas de algumas de suas obras.

Conforme afirma Marisa Lajolo (2002, p. 5) em Descobrindo a Literatura, a literatura traz todo um encantamento do mundo imaginário relacionando-se com o mundo real em que vivemos, assim a:

literatura é algo vivo, que faz parte da vida da gente. Você consegue imaginar um mundo sem histórias contadas, sem poemas, sem canções, sem contos, sem filmes? Pois tudo isso é literatura. Ela abre portas, cutuca, alimenta e nos permite 'dar asas à imaginação'.

Dessa forma, estimular a leitura literária é investir em uma formação humana mais ampla, o que referenda as atividades dos cursos de literatura para a comunidade em geral.

A coordenadora do curso (em todas as edições) foi a professora doutora Mairim Linck Piva e as professoras responsáveis por ministrar a edição de 2011 foram a mestre Sylvia Ayres Cirne, a especialista Cibele H. C. da Costa e a graduada Fernanda M. Johannsen. O curso serviu como incentivo às ministrantes para continuarem seus estudos na área de pós-graduação, bem como estabeleceu-se um núcleo permanente para projetos extensionistas.

Quanto às questões temáticas, o referido projeto tratou acerca da literatura sul-rio-grandense, com foco em alguns temas específicos presentes em significativas obras dessa literatura. Assim no módulo I do curso foram estudados os escritores Fabrício Carpinejar e Tabajara Ruas; no módulo II, observou-se as obras de Italo Ogliari e Caio Fernando Abreu e, por fim, no módulo III, os autores destacados foram Lya Luft e Luiz Antonio de Assis Brasil. Ao final do curso os alunos foram contemplados com registros multimídia, que incluíam o material utilizado ao longo das aulas, 
configurando-se numa produção de material das professoras ministrantes e, ao mesmo tempo, atendendo uma demanda proposta pelos alunos do curso.

Foi possível perceber o grande alcance de público desse tipo de ação extensionista ao termos registrado, além do elevado número de interessados, a participação de alunos de diferentes áreas do conhecimento e níveis de formação, por exemplo, dos cursos de Artes Visuais, Direito, Biologia, Física, Biblioteconomia, Pedagogia, História, Jornalismo, Psicologia, alunos de graduações, programas de mestrado e doutorado da FURG e demais instituições universitárias gaúchas, bem como funcionários universitários e docentes de outras instituições.

Os debates literários desenvolvidos ao longo dos encontros auxiliaram na aproximação entre leitores e obras literárias, pois se considera que o "primeiro passo para a formação do hábito da leitura é a oferta de livros próximos à realidade do leitor, que levantem questões significativas para ele", (AGUIAR e BORDINI, 1993, p.18). Dessa forma, ao participarem ativamente das discussões literárias propostas, enfocando tanto elementos estéticos como temáticos, os participantes se apropriam do universo significado pelas obras, preenchendo suas indeterminações e lacunas em seus horizontes de expectativas.

Além disso, para refletir sobre o papel da literatura, relacionado ao contexto extensionista, consideramos que:

na leitura e na escritura do texto literário encontramos o senso de nós mesmos e da comunidade a que pertencemos. A literatura nos diz o que somos e nos incentiva a desejar e a expressar o mundo por nós mesmos. E isso se dá porque a literatura é uma experiência a ser realizada. É mais que um conhecimento a ser reelaborado, ela é a incorporação do outro em mim sem renúncia da minha própria identidade. (Cosson 2009, p. 17).

Considerando a recepção no retorno da oferta do curso, optou-se por nova edição no segundo semestre de 2012, assim efetivando a terceira oferta do curso "Literatura sul-rio-grandense contemporânea". Mantivemos a proposta e os objetivos iniciais de ampliar o conhecimento referente à literatura produzida pelos escritores do Rio Grande do Sul na contemporaneidade. Além de destacar nomes de relevância na produção literária sulina, atentamos para a discussão em torno das especificidades das estruturas dos textos líricos, narrativos e dramáticos escolhidos. Ao final do semestre, percebemos o despertar de novos olhares acerca dessa produção literária que, de forma efetiva, serviu como incremento para as relações de ensino-aprendizagem e fomentou novas pesquisas na área de estudos literários.

A participação nos cursos ainda tem como resultado o aprimoramento da condição de docentes em constante formação das ministrantes, na medida em que, com a prática, há também uma maior aproximação com as próprias pesquisas em desenvolvimento. Um exemplo é o fato de a maior parte das ministrantes fazer parte também dos grupos de pesquisa "Crítica e Imaginário na literatura sulrio-grandense" e "Imaginário e intimismo: múltiplas representações literárias", fato que demonstra uma importante integração entre ensino e pesquisa.

A visibilidade alcançada pelo curso na universidade fez com que outros docentes se agregassem ao grupo de ministrantes, o que enriqueceu, ainda mais, as discussões tanto no grupo de docentes quanto na sala de aula.

Ainda acerca da edição de 2012, destacamos a integração significativa feita com o ensino básico, visto que na aula inaugural com o cineasta Henrique de Freitas Lima, responsável pela produção cinematográfica da obra Contos Gauchescos, uma professora da rede básica (aluna no curso de extensão) levou seus alunos do $8^{\circ}$ ano para assistirem a fala do cineasta. Com essa ação, cujos resultados extrapolaram as ações iniciais planejadas, pudemos observar o quanto pode ser produtiva a interação entre a universidade e o ensino básico em se tratando de leitura e cultura em geral.

No ano de 2013, mantivemos a oferta no segundo semestre letivo e também a linha temática, sempre com variação nos autores e obras trabalhadas, buscando novas perspectivas sobre essa literatura. Ao final do curso desse ano, optamos por uma ampliação na temática, visto já se ter desenvolvido quatro edições do curso com foco na literatura sulina. 
Pensando o quão significativo é o leitor se aproximar do seu objeto de leitura, optamos por trabalhar com diferentes suportes em que a leitura está presente, considerando que as faixas mais jovens da população interagem de forma mais dinâmica em meios digitais, com suportes de leitura de textos clássicos também veiculados de forma diferenciada, como adaptações e HQs. Afinal, a leitura:

não está no fim do caminho, mas ocupando o lugar da escrita, responsabiliza-se pelo meio - educando pela "pedra", como queria outro poeta, João Cabral de Melo Neto - e pelo interior do trajeto. A leitura intromete-se nos discursos da oralidade, recupera a vitalidade da escrita e concretiza o propósito da linguagem verbal e das demais linguagens, ao absorver e confirmar a informação. (LAJOLO e ZILBERMAN, 2006, p.21).

A partir da proposta de mudança temática, optamos por ofertar o curso intitulado "Literatura: leituras e ensino", no primeiro semestre de 2014. O curso estruturou-se nos seguintes módulos: "Formação de leitores", "Gêneros textuais" e "Literatura e outras linguagens". Um dos objetivos da mudança era buscar maior ligação com as práticas docentes, tentando auxiliar os alunos do curso em suas reflexões pedagógicas, bem como ampliar os olhares de nós, docentes do curso, visto que aprendemos, justamente, nessa troca de saberes que o curso de extensão possibilita.

No módulo inicial, tratamos da formação de leitores, com diferentes enfoques sob a prática da leitura, dadas as perceptivas históricas e as questões atuais acerca da leitura digital. No módulo II, com os gêneros textuais, ampliou-se o corpus com o intuito de que os alunos tivessem contato com o maior número possível de gêneros. No terceiro módulo, trabalhou-se com "literatura e outras linguagens", com um viés interdisciplinar, estabelecendo relações entre literatura e outras áreas do conhecimento, bem como com diferentes meios de expressão (como as HQs, o cinema e a música, por exemplo).

Destaca-se que os docentes dos cursos têm obtido resultados significativos no âmbito acadêmico, com ingresso em programas de mestrado e doutorado na área de Literatura. Muitos dos participantes dos cursos também vêm obtendo êxito nessas seleções e relatam, por vezes, que procuram os cursos para aprofundar e ampliar seus conhecimentos na área de Literatura com vista a aprimoramentos futuros.

Ainda do ano de 2014, houve a oferta de mais um curso na área extensionista, "O imaginário nos contos de fada", ministrado pelas mestrandas Simone Guardalupe e Ana Luisa Cosme e pelo graduando Marco Antonio Muller Filho. O curso se consistiu em um espaço educativo que possibilitasse uma revitalização sobre o gênero conto de fadas e buscou promover sua relevância no ensino para jovens. Para tal, foram enfocados vários contos tradicionais e suas diversas versões e adaptações, procurando tanto analisar seus meandros literários, quanto desvelar suas peculiaridades e valores sociais suscitados por meio de suas imagens simbólicas.

O curso tomou como base, também, o trabalho do grupo de pesquisa "Crítica e imaginário na literatura sul-rio-grandense", no que tange ao referencial teórico utilizado, qual seja, as teorias do Imaginário na linha de Gilbert Durand e Gaston Bachelard. Ao término desse curso, uma nova atividade proposta atingiu resultados além dos esperados. Foi solicitada aos participantes a escritura de contos de fadas inspirados nos modelos estudados, podendo haver atualizações tempo-espaciais. Assim, a resposta a essa proposta foi bastante positiva, tendo-se um número significativo de contos entregues, cogitando-se a possibilidade da organização de uma publicação específica para esse material. Além disso, diversos estudantes de graduação procuraram focar suas pesquisas tanto na área do Imaginário quanto na área de literatura infantil e juvenil, vindo a procurar se integrar nos grupos de pesquisa dessas áreas no Instituto de letras e Artes da FURG. De forma geral, além do contato direto entre os sujeitos envolvidos no trabalho, estabeleceram-se novos diálogos, como os meios on-line (correspondência eletrônica, páginas em redes sociais) e propostas avaliativas dos $\operatorname{cursos}^{4}$ feitas pelos participantes.

Dessa forma, é possível perceber a boa recepção dos cursos em que se propõe a discussão acerca da literatura, com grupos na maioria das vezes heterogêneos. As diversas formas de diálogo exercem papel essencial, tanto para se avaliar a efetividade do alcance dos objetivos das atividades extensionistas propostas, como para auxiliar no planejamento de futuros cursos. A partir das novas propostas temáticas 
implementadas no ano de 2014, pôde-se perceber um aumento da demanda e do interesse dos participantes (com uma evasão menor do que nas edições anteriores).

Em 2015, destacamos a reoferta dos cursos "Literatura: leituras e ensino" e "O imaginário nos contos de fada", com um número bastante expressivo de alunos matriculados.

Além disso, relatamos a criação de um novo curso, "Conto sul-rio-grandense contemporâneo", o qual tem como foco o gênero literário conto e também leva em consideração a produção contista produzida da década de 1970 em diante no Rio Grande do Sul. Foram escolhidos contos dos escritores Daniel Galera, Moacyr Scliar, Michel Laub, Aldyr Garcia Schlee, Caio Fernando Abreu, Cíntia Moscovich e João Gilberto Noll. Para traçar um panorama referente ao estudo do gênero enfocado destacou-se alguns pontos, como sua evolução histórica, a relação com a temática regionalista, as obras de transição temática e a atualização do quadro literário gaúcho a partir dos anos 60, bem como um trabalho sobre as figuras e temas mais destacados. Nos encontros, o diálogo entre literatura e cinema, com abordagem de contos adaptados em curtas gaúchos, tem estimulado os alunos por intermédio de um viés comparatista.

\section{Conclusões}

Com o exposto, vislumbra-se avançar cada vez mais oferecendo atividades de extensão com variadas temáticas, sempre mantendo o foco no estímulo à leitura literária, além de promover um processo continuado de formação de mediadores de leitura, destacando a importância da leitura para a sociedade. Sabe-se que para que um mediador de leitura possa atuar, em especial um docente, devese levar em consideração que, no âmbito escolar, os formadores necessitam de diversos elementos, como salientam Aguiar e Bordini:

Para que a escola possa produzir um ensino eficaz da leitura da obra literária, deve cumprir certos requisitos como: dispor de uma biblioteca bem aparelhada, na área de literatura, com bibliotecários que promovam o livro literário, professores leitores com boa fundamentação teórica e metodológica, programas de ensino que valorizem a literatura e, sobretudo, uma interação democrática e simétrica entre alunado e professor. (AGUIAR e BORDINI, 1993, p. 17)

Portanto, está-se cônscio de que diversos outros fatores de ordem econômica e social devem ser considerados, no entanto, a proposta de cursos abertos à comunidade que promovam o trabalho com textos literários tem-se mostrado também um caminho a ser trilhado. As atividades extensionistas desenvolvidas nos cursos enfocados revelam o quanto o trabalho com a leitura literária é válido e essencial na contemporaneidade. Considerando-se que a:

permanência do gesto básico da leitura faculta a um leitor do presente aproximar-se de um leitor do passado, por mais distintas sejam ou tenham sido suas respectivas práticas de ler, e também permite imaginarmos o comportamento do leitor do futuro. (LAJOLO e ZILBERMAN, 2006, p.30),

Assim a leitura literária continuará sendo um dos fatores decisivos para manutenção da "humanização", que, como salienta Candido, é o processo que:

confirma no homem aqueles traços que reputamos essenciais, como o exercício da reflexão, a aquisição do saber, a boa disposição para com o próximo, o afinamento das emoções, a capacidade de penetrar nos problemas da vida, o senso da beleza, a percepção da complexidade do mundo e dos seres, o cultivo do humor. (CANDIDO, 2004, p.180). 
Nesse sentido, esperamos que, com as práticas extensionistas na área de literatura junto à comunidade, possamos contribuir para um desenvolvimento mais integral dos seres humanos, ampliando sua atuação no mundo e aumentando sua percepção dos elementos que nos unem em uma sociedade mais humanizada pela leitura e pela aceitação da multiplicidade social e individual.

\section{Referências}

AGUIAR, Vera Teixeira de; BORDINI, Maria da Glória. Literatura: a formação do leitor: alternativas metodológicas. Porto Alegre: Mercado Aberto, 1993.

BITTENCOURT, Gilda Neves da Silva. Conto sul-rio-grandense: tradição e modernidade. Porto Alegre: ed. Univ. UFRGS,1999.

CANDIDO, Antonio. Vários escritos. São Paulo/Rio de Janeiro: Duas cidades/ Ouro sobre Azul, 2004.

COSSON, Rildo. Letramento literário: teoria e prática. 1ª ed. $3^{a}$ reimpressão. São Paulo: Contexto, 2009.

CHARTIER, Roger (orgs.). Práticas da leitura. Tradução de Cristiane Nascimento. São Paulo: Estação Liberdade, 2001.

LAJOLO, Marisa; ZILBERMAN, Regina. A formação da leitura no Brasil. São Paulo: Ática, 1996.

LAJOLO, Marisa; ZILBERMAN, Regina. Das tábuas da lei à tela do computador: a leitura em seus discursos. São Paulo: Ática, 2009.

LAJOLO, Marisa. Descobrindo a literatura. São Paulo: Ática, 2002.

LAJOLO, Marisa; ZILBERMAN, Regina. O preço da leitura: leis e números por detrás das letras. São Paulo: Ática, 2001.

${ }^{4}$ No âmbito da Universidade Federal de Viçosa, a AJUP constitui um projeto de extensão vinculado ao Observatório dos Movimentos Sociais. Atualmente, o projeto conta com financiamento de uma bolsa do Programa Institucional de Bolsas de Extensão Universitária da UFV (PIBEX). 